\title{
Students' knowledge and attitudes toward basic life support
}

\author{
Mysara Alfakey, Ahmed Alkarani \\ Department of Nursing, Faculty of Applied Medical Science, Taif University, Saudi Arabia
}

\begin{tabular}{l} 
Article Info \\
\hline Article history: \\
Received Feb 7, 2021 \\
Revised Jun 20, 2021 \\
Accepted Jul 16, 2021 \\
\hline
\end{tabular}

\section{Keywords:}

Basic life support

Nursing students

Saudi Arabia

Training

\begin{abstract}
Students spend a significant proportion of their day in colleges and healthcare facilities where they might experience medical emergencies, or unexpected accidents, that occur in these places. Nursing students are required to perform critical life support in a significant way. The aim of this research was to assess knowledge, attitudes, and training status regarding basic life support (BLS). In Taif University, Saudi Arabia conducted an online cross-sectional survey. The questions used in the questionnaire were prepared according to 2015 American Heart Association (AHA) guidelines. Most subjects $(52.9 \%)$ reported that they had attended a BLS course. The average age of the participants in the sample was 21.64 years. The right responses were significantly affected by previous cardiopulmonary resuscitation (CPR) training $(\mathrm{P}=0.01)$. The students in this study found substantial differences between them: students with previous BLS training (58.3\%) felt capable of offering CPR to their fellow college students, compared to $(42.7 \%)$ in the community without previous training $(\mathrm{P}=0.01)$. Importantly, over all subjects the attitude to learning on a BLS training course was positive. This study concluded that the knowledge, skills and attitudes of trained students are better than those of untrained students.
\end{abstract}

This is an open access article under the CC BY-SA license.

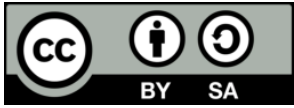

\section{Corresponding Author:}

Ahmed Alkarani

Department of Nursing

College of Applied Medical Sciences, Taif University

Al Mutamarat Rd, Al Mathnah, At Taif 26521, Saudi Arabia

Email: asakg@live.com

\section{INTRODUCTION}

Understanding basic life support (BLS) and cardiopulmonary resuscitation (CPR) is crucial for ensuring that individuals can provide life-saving care in an emergency [1], [2]. This can happen within one hour. Either the heartbeat is insufficient to keep the person alive or the heart stops functioning altogether [3]. Out-of-hospital cardiac arrest is a form of sudden cardiac arrest that occurs outside of a hospital (OHCA). Every year, approximately 60,000 out-of-hospital cardiac arrests (OHCA) occur in the United Kingdom, making it one of the countries with the highest rates of cardiovascular disease (CVD) in the world, with the emergency services attending to half of them [4]. Furthermore, studies suggest that cases in the Middle Eastern and North African (MENA) populations, including Saudi Arabia, will rise dramatically in the coming decades [5]. There will be an increase in the prevalence of cardiovascular diseases as people live longer [6]. In Saudi Arabia, the total number of CVD deaths in 2015 was 25,845, with a CVD death rate of 231.6 per 100,000 . As a result, CVD accounted for more than $40 \%$ of all non-communicable disease-related deaths in Saudi Arabia [7].

The European Resuscitation Council has advocated for a policy that has been endorsed by the World Health Organization: encourage resuscitation education in schoolchildren starting at the age of 12, for 2 hours per year, in all European countries [8]. If even schoolchildren can perform CPR, a young doctor should be 
able to handle a cardiac arrest as well. However, there is a significant lack of awareness about lifesaving techniques among students approaching graduation [9]. The aim of the current study is intended to evaluate the basic life support (BLS) knowledge, training status and attitudes among applied medical science students. It will evaluate their willingness to attend BLS training programmes and compare the knowledge and ability to provide cardiopulmonary resuscitation (CPR) between trained and untrained students.

\section{MATERIAL AND METHODS}

\subsection{Study design and sample selection}

The analysis was conducted between November and December 2020, with a cross-sectional research template and an online web survey tool. The Medical Ethics Research Committee at Taif University in Taif accepted the study protocol with application number 42-0046. Laboratory Science, Physical Therapy, Radiology Science, and General Nursing make up the College of Applied Medical Sciences' fourth department. Data was collected using a self-administered questionnaire to assess students' skills, training status, and attitudes toward BLS. The questionnaire's questions were written in accordance with the 2015 American Heart Association (AHA) guidelines [10]. The participants were chosen using a convenience random sampling process, and 170 students completed the questionnaire.

\subsection{Questionnaires and data collection}

The data were collected by means of questionnaire forms using an online web survey tool which was filled in by the students. A 28-point multiple choice questionnaire was developed specifically for this study. The survey was divided into three sections: 1) Demographics: five questions (gender, age, department, academic level, and marital status); 2) BLS knowledge level: five questions (gender, age, department, two questions about prior training and 15 theoretical or ability questions about familiarity with existing BLS guidelines were included in the survey, including one scenario of cardiac arrest depicting a real-life situation); 3) Attitudes to BLS: five questions were asked, including whether students should be mandated to have BLS training, an investigation of their willingness to learn, their confidence and the barriers to performing BLS.

The main dependent variables in this study are the student's knowledge and skills level, and attitudes to BLS. The main independent variables are the student age, gender, department, academic level, marital status, BLS training status, and the student capability to provide BLS.

Participants were also asked whether they had previously undergone BLS training, and the study population was split into two groups: those who had received training and those who had not. Students were informed about the study's intent, and the questionnaire was completed using an online web survey tool. The AHA and the European Resuscitation Council (ERC) 2015 guidelines were used to assess the proper cardiac arrest signs and BLS procedures. A scoring system was devised, with each correct answer receiving one point and no negative marking. Each participant received a total score.

\subsection{Data analysis}

The study was carried out using the statistical program SPSS 16.0. The t test for normally distributed quantities, the Mann-Whitney U test for non-parametrical variables, and the chi-square test for comparing percentages were used to investigate the differences between qualified and untrained students. Because of the large number of comparisons, we decided to use a $1 \%$ significance level $(\mathrm{p}=0.01)$. For each answer variable, a linear regression model was developed. The standardized coefficients were calculated by taking into account the following factors as independent variables: students' confidence about performing BLS for a victim status (conference or un-conference) age, gender, department, academic level, marital status, BLS course attendance and location of BLS course.

\section{RESULTS}

Table 1 shows the features of the student classes. There were 80 men and 90 women in attendance (7 married vs. 163 single). The average age of the study participants was 21.64 years, with a standard deviation of 2.16 years. There were four department categories: general nursing $(55.3 \%)$ provided the most subjects for the study. 
Table 1. Demographic characteristics and basic life support training status among students

\begin{tabular}{llcc}
\hline \multicolumn{1}{c}{ Characteristics } & N=170 & $\%$ \\
\hline Age & Mean=21.64 & & \\
Gender & SD=2.16 & 80 & 47.1 \\
& Male & 90 & 52.9 \\
Department & Female & 19 & 11.2 \\
& Laboratory science & 36 & 21.2 \\
& Physical therapy & 21 & 12.4 \\
& Radiology science & 94 & 55.3 \\
Academic level & General nursing & 97 & 57.1 \\
& Pre-clinical level & 73 & 42.9 \\
Marital status & Clinical level & 163 & 95.9 \\
& Single & 7 & 4.1 \\
BLS course attendance & Married & 90 & 52.9 \\
& Yes & 80 & 47.1 \\
Location of BLS course & No & 21 & 12.4 \\
& Ministry of Health & 44 & 25.9 \\
& University & 8 & 4.7 \\
& School & 17 & 10 \\
Feel capable to provide BLS & Others & 79 & 46.5 \\
& Nowhere, I didn't attend & 36 & 21.2 \\
& Student & 6 & 3.5 \\
& Co-worker & 15 & 8.8 \\
& Family Member & 0 & 0 \\
& Stranger in a supermarket & 68 & 40 \\
& Anybody & 45 & 26.5 \\
\hline & Nobody & &
\end{tabular}

\subsection{BLS training status}

More than half of the respondents reported having previously taken a BLS course (52.9\%). Most of the trained respondents had obtained their BLS training course in their university $(25.9 \%)$.

\subsection{Evaluation of CPR knowledge and skills}

Figure 1 shows the percentage of correct answers for skills questions and ability demonstration. No student achieved full marks in the questionnaire and only 26 students $(4.8 \%)$ answered over $70 \%(10 / 15)$ of the questions correctly. Students' performance on the knowledge and skills assessment (15 questions) was low.

The median for the correct response for the study population was $5 / 15$ (4/15-7/15). For trained students, it was $6 / 15$ (4/15-8/15) and for untrained students, it was 5/15 (3/15-7/15). Previous CPR training had a significant effect on the correct responses $(\mathrm{P}<0.01)$.

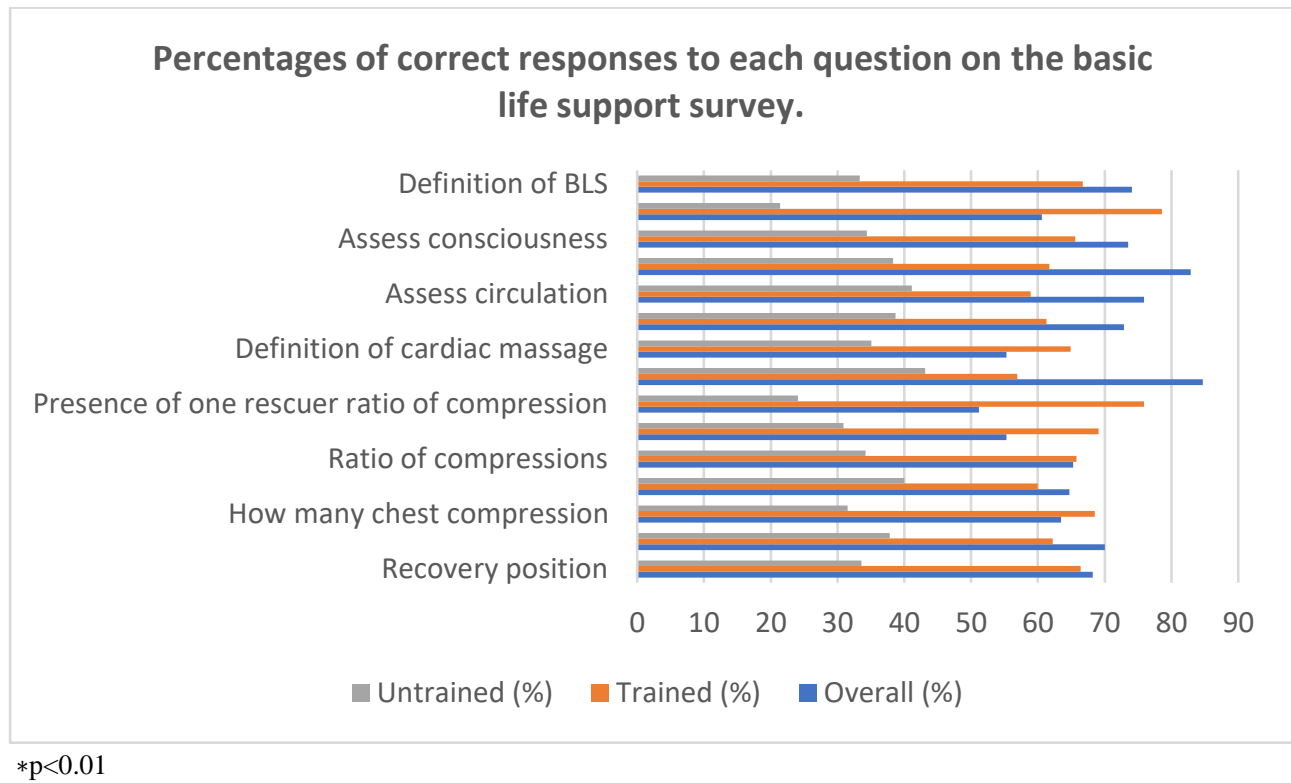

Figure 1. Percentages of correct responses to each question on the basic life support survey in trained and untrained groups 


\subsection{Attitude to BLS}

Our study found strong and significant differences between students: $58.3 \%$ of students with previous BLS training felt capable of providing BLS to their college students compared to $42.7 \%$ in the group without previous training $(\mathrm{P}<0.01)$ as shown in Table 2 . Importantly, overall, the willingness to have BLS training was positive. There were $86 \%$ students eager to attend a BLS course. Furthermore, trained students had a more positive attitude than untrained students and there were significant differences between trained and untrained students regarding their willingness to learn BLS training $(\mathrm{p}<0.01)$. Moreover, $61 \%$ of students reported that BLS training was not mandatory for students at their college.

Table 2. Training status and feeling capable of providing BLS

\begin{tabular}{|c|c|c|c|}
\hline Question Title & Trained (percentage) & Untrained (percentage) & $P$ value \\
\hline Feel capable to provide BLS to & & & $<0.01^{*}$ \\
\hline Student & $21 / 91(58.3 \%)$ & $15 / 79(41.7 \%)$ & \\
\hline Co-worker & 4/91 (66.7\%) & 2/79 (33.3\%) & \\
\hline Family member & $9 / 91(60 \%)$ & $6 / 79(7.6 \%)$ & \\
\hline Anybody & $56 / 91(82.4 \%)$ & $12 / 79(17.6 \%)$ & \\
\hline Nobody & $1 / 91(2.2 \%)$ & $44 / 79(97.8 \%)$ & \\
\hline
\end{tabular}

There were significant differences between trained and untrained students regarding their confidence about performing BLS for a victim (59.8\% trained, $40.2 \%$ untrained, $\mathrm{p}<0.05)$. Overall, $28.2 \%$ of students reported that they did not feel confident about performing BLS for a victim. Participants were asked about the barriers to performing BLS: $44.6 \%$ trained and 55.4\% untrained students reported that conducting CPR incorrectly was a barrier likely to prevent them from performing BLS ( $\mathrm{p}>0.01)$ as shown in Table 3.

Table 3. Training status, scenario, attitude and barriers to performing BLS

\begin{tabular}{|c|c|c|c|c|c|}
\hline & & $\begin{array}{l}\text { Overall } \\
(\%)\end{array}$ & $\begin{array}{l}\text { Trained } \\
(\%)\end{array}$ & $\begin{array}{l}\text { Untrained } \\
(\%)\end{array}$ & $P$ \\
\hline \multirow{6}{*}{$\begin{array}{l}\text { A student develops cardiac arrest } \\
\text { due to respiratory failure when no } \\
\text { one is there except you, what } \\
\text { would you do? (Scenario) } n=170\end{array}$} & $\begin{array}{l}\text { You would call Emergency Medical Services } \\
\text { (EMS) and then start to resuscitate the victim }\end{array}$ & 68.8 & 53.0 & 47.0 & \multirow[t]{6}{*}{0.983} \\
\hline & $\begin{array}{l}\text { You would start to resuscitation and then call } \\
\text { EMS }\end{array}$ & 14.1 & 58.3 & 41.7 & \\
\hline & $\begin{array}{c}\text { You did not know what to do in such a } \\
\text { situation }\end{array}$ & 6.5 & 27.3 & 72.7 & \\
\hline & $\begin{array}{l}\text { You would call EMS and would not start to } \\
\text { resuscitation }\end{array}$ & 2.4 & 50.0 & 50.0 & \\
\hline & $\begin{array}{c}\text { You would notify the college principal and } \\
\text { would not start resuscitation }\end{array}$ & 4.7 & 50.0 & 50.0 & \\
\hline & $\begin{array}{l}\text { You would notify the school headmaster and } \\
\text { start to resuscitation }\end{array}$ & 3.5 & 83.3 & 16.7 & \\
\hline Did your college mandated you to & Yes & 38.8 & 59.1 & 40.9 & \multirow[t]{2}{*}{0.202} \\
\hline have BLS training? $\mathrm{N}=170$ & No & 61.2 & 49.0 & 51 & \\
\hline Are you willing to learn BLS & Yes & 86.5 & 56.3 & 43.5 & \multirow[t]{2}{*}{0.020} \\
\hline training? $\mathrm{N}=170$ & No & 13.5 & 30.4 & 69.6 & \\
\hline Are you confidence to perform & Yes & 71.8 & 59.8 & 40.2 & \multirow[t]{2}{*}{$<.01$} \\
\hline BLS for a victim? $\mathrm{N}=170$ & No & 28.2 & 35.4 & 64.6 & \\
\hline what the barriers to perform BLS? & Conducting CPR incorrectly & 32.9 & 44.6 & 55.4 & \multirow[t]{4}{*}{0.374} \\
\hline \multirow[t]{3}{*}{$\mathrm{N}=170$} & In confidence to perform $\mathrm{CPR}$ & 16.5 & 60.7 & 39.3 & \\
\hline & Fear & 25.9 & 59.1 & 40.9 & \\
\hline & Afraid of consequence of CPR & 24.7 & 52.4 & 47.6 & \\
\hline
\end{tabular}

One cardiac arrest scenario was presented: a fellow student develops cardiac arrest due to respiratory failure when no one is there except the respondent. The results were as: $14 \%$ responded correctly that they would start resuscitation and then call EMS. About, (58.3\%) vs (41.7\%) of trained and untrained students, respectively, responded correctly to the scenario.

After taking into account other sociodemographic and educational factors, the multiple linear regression analyses overall model summary showed $\mathrm{R}^{2}=.60$; the predictors age, gender, department, academic level, marital status and BLS course attendance account for $60 \%$ of the variance in student confidence about performing BLS for a victim, next, ANOVA table (alpha=.05 in the test). F $(3,168)=8.51$, P.001 R2=.60 was a significant regression model overall. Moreover, only department and BLS course 
attendance significant remained. The correlations of variables predicting students' confidence in performing BLS for a victim are shown in Table 4, which shows the correlates of variables predicting students' confidence in performing BLS for a victim department; $(\beta=0.231, \mathrm{p} 0.01)$. Participants who had previously completed BLS training were more secure in performing BLS on a victim $(\beta=0.282, \mathrm{p} 0.01)$. Age $(\beta=-0.033$, $p=.720)$, gender $(\beta=0.023, p=0.771)$, academic level $(\beta=0.056, p 0.520)$, and marital status $(\beta=-0.060$, $\mathrm{p}=0.442$ ) were all non-significant sociodemographic and educational variables.

Table 4. Results of multiple linear regression tests of variables that predict confidence about performing BLS

\begin{tabular}{ccccc}
\multicolumn{5}{c}{ for a victim } \\
\hline & $\beta$ & $95 \%$ Confidence interval & $p$ \\
\hline Age & -0.033 & -0.045 & 0.031 & 0.720 \\
Gender & 0.023 & -0.119 & 0.160 & 0.771 \\
Department & 0.231 & 0.027 & 0.163 & $<0.01^{*}$ \\
Academic level & 0.056 & -0.104 & 0.205 & 0.520 \\
Marital Status & -0.060 & -0.390 & 0.171 & 0.442 \\
BLS course attendance & 0.282 & 0.111 & 0.408 & $<0.01^{*}$ \\
\hline $\mathrm{p}<.01$ & & & &
\end{tabular}

\section{DISCUSSION}

To boost BLS training in the pre-graduation level, it may be appropriate to make BLS training a requirement for medical students to graduate. The aim of this study was to assess basic life support (BLS) skills, training, and attitudes among students at Taif University (TU) in Saudi Arabia's college of applied medical sciences. Out of 170 understudies who took part in this study, more than half of the respondents detailed already having taken a BLS course (52.9\%). None of the participants replied all the questions correctly. The middle for the right reaction for the study population was $5 / 15$ (4/15-7/15). For trained understudies, it was 6/15 (4/15-8/15) and for untrained understudies, it was 5/15 (3/15-7/15). Past CPR preparing had a critical impact on the right reactions $(\mathrm{P}<0.01)$, proving the study by Yousef, et al. [11]. Out of 370 medical students who participated in this study, $41 \%$ had received BLS training more than once, while $59 \%$ had received only a mandatory BLS course during their second academic year. None of the participants answered all the questions correctly. Although students who had received more than one BLS training scored higher (41.5\% correct answers) than the students who had only had the mandatory class (39.5\% mean correct answers), the difference in the scores was narrow and both showed a mean less than 50\%, which was unsatisfactory these results are consistent with previous Saudi Arabian study, which has consistently found low BLS awareness [12], [13]. Furthermore, several countries have recorded low BLS awareness scores among health students [14]-[16].

Studies show that poorly performed and inefficient chest compressions and rescue breaths prevent successful CPR, while high-quality standard CPR produces $25-33 \%$ of normal cardiac production and oxygen delivery; as a result, competency in these two basic skills is essential [17], [18]. The research also revealed major differences between students: students with previous BLS training (58.3\%) felt capable of delivering BLS to their peers, compared to students without previous BLS training $(42.7 \%)(\mathrm{P}=0.01)$. Other international studies have found that As BLS training is critical for improving knowledge and self-confidence in performing BLS when needed [19]-[21]. This may indicate that prior CPR experience is linked to greater CPR awareness. In our research, the most common obstacle to performing BLS when it was required was performing CPR incorrectly due to fear of the effects of CPR and a lack of confidence. Other research, on the other hand, found that the most common obstacle to conducting BLS was a lack of knowledge of the procedure. Training has been shown in studies to increase the ability to perform BLS [22].

Most of the subjects in this study were willing to attend a BLS training course. Some $86 \%$ of the students were eager to do so. Furthermore, trained students had a more positive attitude than untrained students, and there were significant differences between trained and untrained students regarding their willingness to learn BLS training $(\mathrm{p}<0.01)$. Moreover, $(61 \%)$ of students reported that BLS training was not mandatory for students at their college. This result indicated that they had a strong belief in the value of BLS preparation. In contrast to this result, a study of health interns from different Saudi Arabian universities found that up to $70 \%$ of students believe BLS training should be included in college curricula [23]. A study has suggested that a BLS training course be included in the college curriculum to provide early exposure to BLS knowledge [20].

Moreover, our current study demonstrated a relationship between the department and BLS course attendance having an impact on confidence about performing BLS for a victim. The participants who had previous BLS training felt more confident about performing BLS for a victim $(\beta=0.282, p<0.01)$. We did not find a correlation between confidence about performing BLS for a victim and students' age, gender and 
academic level, in contrast to the study by Khalid, et al. [24] Training had an effect on general understanding and knowledge of CPR, according to the report. When one's educational level rose, so did their awareness. It has been recorded that individual who are older, less qualified, and have a lower income have a lower likelihood of CPR trust [25]-[29].

Finally, our current study revealed that many students $(n=68 / 170,40 \%)$ did not correctly identify cardiac arrest. In the case of cardiac arrest, another important aspect is the early activation of the emergency medical service. Rescuers should learn how and when to call the EMS. In this study, participants were presented a scenario in which a student develops cardiac arrest due to respiratory failure. However, in their responses, $68.8 \%$ of the participants said that they would call for help before trying to resuscitate the victim. This indicates that most of the participants do not know exactly when to call the EMS for help. This finding agreed with another study carried out in Turkey by Dursun, et al. [30], which observed almost the same result. Most teachers $(n=330,61 \%)$ did not correctly identify cardiac arrest. In the case of cardiac arrest, another important aspect is the early activation of the emergency medical service. Rescuers should learn how and when to call the EMS. In this study, participants were presented with a scenario in which a student develops cardiac arrest due to respiratory failure. However, in their responses, $81 \%$ of the participants said that they would call for help before trying to resuscitate the victim.

Students understand the value of BLS and are eager to participate in a BLS training course to further their awareness and skills. Despite the fact that qualified students' expertise was found to be superior to that of untrained students.

\section{CONCLUSION}

This study found that over all respondents, the attitude to learning on a basic life support (BLS) training course was positive. The study concluded that the knowledge, skills and attitudes of trained students are better than those of untrained students.

Our findings suggested that efficient and consistent cardiopulmonary resuscitation (CPR) preparation is important. Both health-care agencies and individual providers should be involved in ensuring that certain courses are attempted and completed, in order to increase trust in CPR success and potentially save lives. Future research is needed to assess the effects of different BLS preparation frequencies and groups on success in crisis situations.

\section{REFERENCES}

[1] F. Bhanji, et al., "Part 14: Education - 2015 American Heart Association guidelines update for cardiopulmonary resuscitation and emergency cardiovascular care," Circulation, vol. 132, no. 18, pp. 561-573, 2015, doi: 10.1161/CIR.0000000000000268

[2] B.K. Kanstad, S.A. Nilsen, and K. Fredriksen, "CPR knowledge and attitude to performing bystander CPR among secondary school students in Norway," Resuscitation, vol. 82, no. 8, pp. 1053-1059, 2011, doi: 10.1016/j.resuscitation.2011.03.033.

[3] I.M. Asif and K.G. Harmon, "Incidence and etiology of sudden cardiac death: new updates for athletic departments," Sports Health, vol. 9, no. 3, pp. 268-279, 2017, doi: 10.1177/1941738117694153.

[4] C. Hawkes, et al., "Epidemiology and outcomes from out-of-hospital cardiac arrests in England," Resuscitation, vol. 110, no. 1, pp. 133-40, 2017, doi: 10.1016/j.resuscitation.2016.10.030.

[5] L. Raffee, et al., "Final Year Dental Students' Perception of Knowledge, Training and Competence in Medical Emergency Management," Glob J Health Sci, vol. 10, no. 6, pp. 1-9, 2018, doi: 10.5539/gjhs.v10n6p1.

[6] M.J. Prince, et al., "The burden of disease in older people and implications for health policy and practice," The Lancet, vol. 385, no. 9967, pp.549-562, 2015, doi: 10.1016/S0140-6736(14)61347-7.

[7] GBD 2015 Eastern Mediterranean Region Cardiovascular Disease Collaborators, A. Tehrani-Banihashemi, M. Moradi-Lakeh, et al., "Burden of cardiovascular diseases in the Eastern Mediterranean Region, 1990-2015: Findings from the Global Burden of Disease 2015 study," Int. J. Public Health, vol. 63, no. 1, pp. 137-149, 2018, doi: 10.1007/s00038-017-1012-3.

[8] B.W. Bottiger and H. Van Aken, "Kids save lives-training school children in cardiopulmonary resuscitation worldwide is now endorsed by the World Health Organization (WHO)," Resuscitation, vol. 94, 2015, doi: 10.1016/j.resuscitation.2015.07.005.

[9] E. Contri, M.C. Bonomo, G. Costantini, et al., "Are final year medical students ready to save lives in Italy? Not yet," Emerg. Med. J, vol. 34, no. 8, p. 556, 2017, doi: 10.1136/emermed-2017-206748.

[10] D.L. Atkins, et al., "Part 11: Pediatric Basic Life Support and Cardiopulmonary Resuscitation Quality: 2015 American Heart Association Guidelines Update for Cardiopulmonary Resuscitation and Emergency Cardiovascular Care," Circulation, vol. 132, no. 18, pp. 519-525, 2015, doi: 10.1161/CIR.0000000000000265.

[11] Y. Z. Khedher, L. Shawwa, A. A. Alamri, M. M. Farraj, and M. E. Bayoumi "Knowledge and Attitude of Basic Life Support among Medical Students at King Abdul-Aziz University," The Egyptian Journal of Hospital Medicine, vol. 69, no. 8, pp. 3066-3076, 2017, doi: 10.12816/0042857. 
[12] A. Alanazi, M. Bin-Hotan, H. Alqahtani, A. Alhalyabah, A. Alanazi, and S. Al-Oraibi, "Community awareness about cardiopulmonary resuscitation among secondary school students in Riyadh," World J Med Sci, vol. 8, no. 3, pp. 186-189, 2013, doi: 10.5829/idosi.wjms.2013.8.3.7337.

[13] O.A. Alotaibi, F. Alamri, L. Almufleh, and W. Alsougi, "Basic life support: Knowledge and attitude among dental students and staff in the College of Dentistry, King Saud University," Saudi J Dent Res, vol. 7, no. 1, pp. 51-56, 2016, doi: 10.1016/j.sjdr.2015.06.001.

[14] S. Chandrasekaran, S. Kumar, S.A. Bhat, Saravanakumar, P.M. Shabbir, and V. Chandrasekaran, "Awareness of basic life support among medical, dental, nursing students and doctors," Indian J Anaesth, vol. 54, no. 2, pp. 121126, 2010, doi: 10.4103/0019-5049.63650.

[15] H. Zaheer and Z. Haque, "Awareness about BLS (CPR) among medical students: Status and requirements," J Pak Med Assoc, vol. 59, no. 1, pp. 57-59, 2009.

[16] C. M. G. Phadraig, et al., "Neither basic life support knowledge nor self-efficacy is predictive of skills among dental students," Eur J Dent Educ, vol. 21, no. 3, pp. 187-192, 2016, doi: 10.1111/eje.12199.

[17] R.W. Neumar, et al., "Part 1: Executive summary - 2015 American Heart Association guidelines update for cardiopulmonary resuscitation and emergency cardiovascular care," Circulation, vol. 132, no. 18, pp. 315-367, 2015, doi: 10.1161/CIR.0000000000000252.

[18] G.D. Perkins, et al., "European Resuscitation Council guidelines for resuscitation 2015: Section 2 - Adult basic life support and automated external defibrillation," Resuscitation, vol. 95, no. 1, pp. 81-99, 2015, doi: 10.1016/j.resuscitation.2015.07.015.

[19] R.R. Chandra, S.K. Kilari, S.L. Uppalapati, A.K. Bathula, M.K. Mopuri, and S. Katragadda, "Introduction of Basic Life Support in Medical Curriculum-Is this the Need of an Hour?" J. Evol. Med. Dent. Sci. vol. 8, no. 1, pp. 2982 2986, 2019.

[20] S. Pande, S. Pande, V. Parate, S. Pande, and N. Sukhsohale, "Evaluation of retention of knowledge and skills imparted to first-year medical students through basic life support training," Adv Physiol Educ, vol. 38, no. 1, pp. 42-45, 2014, doi: 10.1152/advan.00102.2013.

[21] A. Abbas, S.I. Bukhari, and F. Ahmad, "Knowledge of first aid and basic life support amongst medical students: A comparison between trained and un-trained students," J Pak Med Assoc, vol. 61, no. 1, pp. 613-616, 2011.

[22] W. Tsegaye, M. Tesfaye, and M. Alemu, "Knowledge, attitude and practice of cardiopulmonary resuscitation and associated factors in Ethiopian university medical students," J. Gen. Pract., vol. 3, no. 4, pp. 1-5, 2015, doi: 10.4172/2329-9126.1000206.

[23] S.A. Saquib, et al., "Knowledge and Attitude about Basic Life Support and Emergency Medical Services amongst Healthcare Interns in University Hospitals: A Cross-Sectional Study," Emerg. Med. Int., vol. 2019, no. 1, pp. 1-8, 2019, doi: 10.1155/2019/9342892.

[24] F. K. Alquwaiay, et al., "Assessment of the levels of awareness toward cardiopulmonary resuscitation: A community-based study in Northern Saudi Arabia," J Educ Health Promot., Vol. 7, p. 167, 2018.

[25] A.L. Blewer, et al., "Cardiopulmonary resuscitation training disparities in the United States," J Am Heart Assoc, vol. 6, no. 5, p. e006124, 2017.

[26] Ş. Özbilgin, M. Akan, V. Hanc1, C. Aygün, and B. Kuvaki, "Evaluation of public awareness, knowledge and attitudes about cardiopulmonary resuscitation: Report of Izmir," Turk J Anaesthesiol Reanim, vol. 43, no. 6, pp. 396-405, 2015, doi: 10.5152/TJAR.2015.61587.

[27] M.W. Butler and A.O. Adefuye, "Assessing the knowledge of emergency medical care personnel in the Free State, South Africa, on aspects of paediatric pre-hospital emergency care," Pan Afr Med J, vol. 32, no. 98, 2019.

[28] J.D. Mothibi, M. Jama, and A.O. Adefuye, "Assessing the knowledge of emergency medical care practitioners in the Free State, South Africa, on aspects of pre-hospital management of psychiatric emergencies," Pan Afr Med J, vol. 33, no. 132, pp. 1-10, 2019, doi: 10.11604/pamj.2019.33.132.18426.

[29] P. Asadi, S.M..Z Ziabari, J. Vatani, J. Ghotbi, and F. Safaee, "Assessing the knowledge of Guilan Pre-Hospital emergency personnel (EMS) from safety principles," J Adv Pharmacy Education Res, vol. 9, no. 2, pp. 98-105, 2019.

[30] A. Dursun, S. Özsoylu, B. Emeklioğlu, and B. N. Akyıldız, "Evaluating the basic life support knowledge among schoolteachers: A cross-sectional survey in Kayseri, Turkey," The Turkish Journal of Pediatrics, vol. 60, no. 6, pp. 702-708, 2018, doi: 10.24953/turkjped.2018.06.011. 